\title{
THE PROBLEM OF SOCIOLOGY.
}

The overthrow of the individualistic point of view may be considered the most important and fruitful step which historical science and the moral sciences (Geisteswissenschaften) generally have made in our time. In place of the individual careers which formerly stood in the foreground of our picture of history, we now regard social forces, national movements, as the real and determining factors, out of which the parts which individuals play cannot be evaluated with complete definiteness. The science of human beings has become the science of human society. No object of discussion in the moral sciences can avoid this tendency. Even where movements culminate in the individual, as in the realm of art, we seek the causes in the evolution of the race, from which we have arrived at a perception of the beautiful, and in the particular social condition of the time, which made possible just this or that form of artistic product. In the realm of religion, as in that of economic life; in the realm of morals, as well as in technical progress; in politics, as well as in those things which treat of the health and disease of body and soul, it is equally true that we find a tendency to refer each single fact back to the historical condition, the needs and efforts of the entire society concerned.

Notwithstanding the fact that this tendency in thought is so generally and manifestly present, it can furnish at best only a regulative principle for the moral sciences, and can on that account never constitute an independent science with a place of its own in the group of moral sciences. If sociology really comprehends, as has been supposed, the sum of social facts and the reduction of single events to a [4I2] 
social basis, it is nothing more than a group-name for the totality of the moral sciences as treated in modern times. In this way those empty generalities and abstractions which brought about the ruin of philosophy have found place even in sociology. Like philosophy, it will attempt to force into a purely imaginary or external unity those things which do not belong together, and create a scientific world-empire which must break asunder just as surely as political worldempires have been severed into separate kingdoms. Sociology, as history of society, and of all that it contains, that is in the sense of an explanation of all events in terms of social forces and configurations, is no more an independent science than induction for example. Sociology like induction-only not in so formal a sense-is a method of investigation (Erkenntnissmethode), a directive principle which can be made fruitful in an endless number of the most different fields of science, without itself being a science.

If sociology then, in place of a mere tendency in method, which has been falsely denoted the science of sociology, is to be a true science, the entire province of social science in its broadest sense must be divided for purposes of investigation, and a sociology, in the narrower sense, be separated out. Psychology furnishes a good basis of comparison for the real way in which this differentiation must take place. The attempt has been made to solve the problems of all sciences in psychology; since only within the realm of consciousness were to be found the objects of perception, it was argued that these latter can only be explained through psychological forces and according to the psychological laws which produced them. In spite of this position, however, psychology is generally differentiated as a science of the functions of the mind, as such, and rightly separated from the special sciences which from particular points of view investigate the particular contents of perceptive knowledge. Psychology deals with the abstraction,--comprehensive or limited to particular departments-of "functions," 
"powers," "norms," or, however it may be designated, with that which bears the same relation to the concrete activities of the mind that law, type, general, bear to particular, or that the form bears to the formed content. Everything that happens is an event in the mind, it is also, from another point of view, an event in society; but just as psychology does not deal with everything conditioned by consciousness, so sociology does not necessarily include everything that belongs in society or that is conditioned by its existence. Psychology, as a science, springs rather from the differentiation of the specifically psychical from its objective material basis, and, sociology likewise, should treat of the specifically social, the process and forms of socialization, as such, in contrast to the interests and contents which find expression in socialization (Vergesellschaf. tung). These interests and aims form the subject-matter of special-technical or historical-sciences; through the circle of these sciences, sociology traces a new one, which includes and marks off on each the peculiar social powers and elements, the forms of association, as such.

Society, in its broadest sense, is found wherever several individuals enter into reciprocal relations. From a purely ephemeral association for the purpose of a casual promenade, to the complete unity of a family, or a guild of the Middle Ages, one must recognize socialization of the most varying kind and degree. The particular causes and aims, without which socialization never takes place, comprise, to a certain extent, the body, the material of the social process. That the result of these causes, and the pursuance of these aims call forth, among the persons concerned, a reciprocal relationship, or a socialization, this is the form, in which the content of social organization clothes itself. The entire existence of a special science of society rests upon the isolation of this form by means of scientific abstraction. For it is evident that the same form and the same kind of socialization, can arise in connection with the most varied elements [4I4] 
and take place for the most diverse ends. Socialization, in general, takes place, as well in a religious congregation as in a band of conspirators, in a trust as well as in a school of art, in a public gathering as well as in a family; and we find also certain formal similarities in the special characteristics and development of all such unions. We find, for example, the same forms of authority and subordination, of competition, imitation, opposition, division of labor, in social groups which are the most different possible in their aims and their moral character. We find the formation of a hierarchy, the embodiment of the group-forming principle in symbols, the division in parties, all stages of freedom or restriction of the individual in relation to the group, interaction and stratification of groups themselves, and definite forms of reaction against external influences. This similarity of form and its development, in the case of groups often with the most complete heterogeneity of material conditions reveals forces lying back of these immediate conditions, and suggests the possibility of constituting by abstraction a legitimate realin of investigation, namely, that of socialization as such and the study of its forms. These forms are evolved through contact of individuals, but relatively independent of the basis of such contact, and their sum make up that concrete thing which we designate by the abstraction-society.*

* A common inexactness is that which classifies every ethnological investigation and research in primitive conditions within the province of sociology. We forget in so doing that acts and conditions often appear to belong to society only because our knowledge of them is too inexact to determine the purely individualistic events, which are the real ones. From a great distance, a whole series of personalities and individual acts intermingle, and form for the mental eye a concrete mass, Society-just as one from a great distance does not see the single trees ot a forest, but sees only the forest. It is true that etlinology and researches in primitive conditions are of the highest value for the real science of society, that is, for the knowledge of the developed powers, results and conditions which have come through socialization. But, to include such general outines under the concept of sociology, is to make a faulty distinction between that "society" which is only a collective name arising from our inability to treat singly the separate phenomena, and that society which determines such phenomena through specific social forces. We often designate purely parallel phenomena, in a mass, as social, and confuse statistical similarities and synchronisus 
It is true that content and social form are in reality mixed in each particular historical event; there is no social constitution or development which is merely social and not, at the same time, a constitution or development of a content. This content may be of an objective kind, the production of a work, the progress of the mechanical arts, the domination of an idea, the success or failure of a political combination, the development of language, of customs, etc., or, it may be of a subjective nature, and concern the innumerable sides of personality which through socialization find stimulus, satisfaction and development, now towards a refinement, now towards a deterioration of morals. This immediate unification of content and form which we find in historical reality does not prevent their separation for scientific purposes; geometry, for instance, deals with the mere spaceforms of bodies which do not exist as forms, but only in connection with matter, the investigation of which belongs to other sciences.

The historian also, in the narrower sense, treats of nothing but an abstraction from the world of real events. Out of the infinitude of real words and deeds and the sum of all the single subjective and objective events he tries to trace the development as far as it may be brought under certain fixed concepts. Not everything that Frederick II. or Maria Theresa did from morning until night, nor even the accidental words in which they clothed their political decisions, are related in history, and much less the innumerable psychical events which in reality were indissolubly linked with these decisions, but occurred without relation to their content. It is rather the concept of the politically important which is brought to bear on the real events, and only that is sought out and enumerated which has to do with this concept, but which may, in this very continuity and coherence,

of a purely individual nature, with those which can be referred back to the real principle of society, the reciprocity of cause. So we do not make the required distinction between that which takes place merely within society, as within a frame, and that which comes to pass through society. 
never have occurred. Thus, economic history isolates all that which belongs to the bodily needs of men, and the means to their satisfaction, from the totality of events-although at the same time, there is, perhaps, none among these which does not stand in some direct relation to these needs. Sociology, as a special science, must proceed in the same way. It must separate out as an object of special investigation the purely social elements from the totality of human history, or, to express the same thought with paradoxical brevity, it discusses that which in society is "Society." *

The methods, by which the problems of socialization are to be investigated, are the same as in all comparative psychological sciences. Certain psychological premises lie at the

* If, as I believe, the investigation of the forces, forms and development of socialization, of co-operation, of association of individuals, sbould be the single object of sociology as a special science, we must include a study of the peculiar characteristics of the forms which socializations take on under the influence of particular environments in which they are realized. If, for example, we investigate the formation of aristocracies, we must not only examine the process of separation of the originally homogeneous masses, and the bond of association of the leaders in a class unity, and the degree of repulsion which such unions manifest toward ruling sovereigns as well as toward the masses, but in addition to these elements, we must take into consideration the material interests which generally call forth such organization, and also the modifications which different stages of production and variations in the dominating ideas of the time bring about. Many characteristics too within the field of social phenomena, which in themselves seem to be essentially individual become thoroughly social as soon as our conception of social forms is broad enough; for example, secret societies constitute a peculiar sociological problem. What effect has secrecy upon association, and what special forms does it take when this condition is attached? Why do associations most dissimilar when not secret show a tendency to follow a certain similar line of development as soon as they become secret? While here the socialization appears to be determined by an extra-social prnciple, we find on closer observation that secrecy belongs, in its real essence, among the forms of social life. It arises exclusively where a union of individuals is found, and is a certain form of their reciprocal relationship, which is in no sense of a merely negative nature, but rather an entirely positive and reciprocal bond. Again association and combination, in the narrower sense, are not the only forms of relationship among men which belong in sociology as a science; also, associations in the broader sense of opposition, competition, are the basis of relationships which show reciprocal action among individuals prompted, perhaps, by the most different kinds of causes, but finding expression in similar forms and in a similar development. They point to forces which are developed by the competitive contact of men with each other, and the kinds and sources of which must be studied by themselves in order to know how the most extraordinary diversity of motives and objects in single cases nevertheless causes a similarity in the form of association. 
bottom without which no science of history can exist at all. The phenomena of seeking and giving help, of love and hate, of avarice and of pleasure in social intercourse, self-preservation through competition on the one hand and on the other through combination, and a host of other primary psychical facts must be assumed, in order that we may at all understand the processes of socialization, formation of groups, relationships that individuals sustain to group units, etc. Just as a clear and connected economic history, together with those inductions which one may regard as approximate economic principles, is written only by culling from the sum of historical circumstances those which spring from certain physical, and yet no less psychical, needs or wants, so there is a science of society because certain specific formations within that historical complex may be referred to psychical states and actions which proceed only from social contact, from the interaction of groups and individuals one upon another.

The investigation may take two courses. It follows first the longitudinal direction of a particular evolution. Thus, for example, the history of the Germanic tribe, or of the parties in England, or of the forms of the Roman family, or of a trade-union, or of the constitution of a church, is in so far sociological as social forms,-authority and subordination, the formation of an objective union as over against the mere sum of individuals, the growth of subdivisions, the modification of the social form through the quantitative changes in the group,-appear in the complex of phenomena. There is, in the second place, a cross-sectional view of such evolutions, which paralyzes the material differences of the individuals and lays bare by induction that which is common to them all, the social forms, as such. These may be those general relations and changes which are called forth by the constant individual similarities and differences in the persons comprising every form of union; or those special forms of association which are found in the socializations of a definite [4I 8] 
territory or object-economic, religious, domestic, social, political -or of a particular period.

This special task of sociology must be separated strictly from the philosophy of history. The philosophy of history seeks to bring historical facts, external as well as psychical, in their entirety, under general concepts, by virtue of which history may satisfy certain demands, ethical, metaphysical, religious and artistic. In complete opposition to this, sociology as a special science, the eventual scope of which $I$ have attempted here to determine, restricts itself entirely to the realm of phenomena and their immediate psychological explanation. In only one direction do I wish to add a speculative thought to the entire problem of sociology. There is to-day scarcely a doubt that laws of history are not to be found. For history is, on the one hand, so extremely complex, and on the other it deals with so uncertain and arbitrary a section of the totality of cosmical events, that there cannot possibly be a unified formula for its development as a whole.* If we do not wish to give up the hope that we may comprehend history as a development, subject to law, the way to such an understanding must lie through the analysis of history into divisions as simple and homogeneous as possible. Just as the history of one country cannot be understood directly as an undivided whole, but rather through the separate consideration of its agricultural conditions, of its social and national politics, of its intellectual culture, of its industry and system of education, etc., so history in general is a series of special sciences whose objects, it is true, do not appear separately, and only in combination make possible the combined idea of history; but they allow of an approach to law only in that simplified form. The proposition which I make here, respecting the scope of sociology, in order to protect it from ending in a mere method for other sciences, or in a merely

\footnotetext{
* For further proof of this, see my "Probleme der Geschichtsphilosophie," Cap. ii.
} 
new word for the complex of historical science-may, perhaps, be found to be a further contribution in the analysis of the aggregate of historical facts, in so far as it separates out the function of socialization in its innumerable forms and developments as a special field. This special field, through its qualitative simplicity, makes less chimerical the discovery of specific laws than the complex historical order did so long as it did not differentiate its special elements, forms and contents. It is further a special field in whichit matters not whether we give it the title of a special science, or the more important one of a collection of tasks (Aufgabensammlung) -we may arrest the error of the current conceptions of sociology, and in which can be grounded a good claim to a territory with indisputable boundaries, after all high-flown claims have been abandoned.

\section{SUPPLEMENTARY NOTE.}

Since the first publication* of the preceding paper, the objection has been made that I unnecessarily limited the scope of Sociology. In the first place I did not consider it important to set up a new definition of Sociology, but rather to direct attention to a number of problems closely related to each other, but which in this particular relation and in this unity had not yet been considered together. Just what name to give this group is quite unimportant since the real question is to state problems and to solve them and not at all to discuss the names which we should give to particular groups of them. I have chosen for those problems that I have described above the name Sociology because it seemed to me as if the things which are commonly treated under this title are already handled by other sciences. Political

\footnotetext{
*In Schmoller's Jahrbuch für Gesetzgebung, Verwallung und Volkswirtschaft im Deutschen Reiche. 1894.
} 
Economy, Constitutional History, Ethnology, Statistics, History of Civilization and a number of other sciences have already divided up the entire realm of social facts. Each of these occupies itself with events and laws which manifest themselves within society. The discovery of new material facts cannot generally be held to be incumbent on Sociology as a new science, but rather the working over of the ascertained facts and their presentation through abstraction and combination, from a new point of view, the essence of which seemed to me to consist in the separation of content and form of social events. All the aforesaid sciences treat of social events in so far as they divide them to suit their subject-matter into the economic, legal, political events, which make up the fixed divisions of social life dealt with in these sciences. On the other hand, there is no science which treats of the social life merely as such and without reference to particular aims and purposes. Political Economy for example, as also Political History, and the History of Religion as well as that of Art, has much to do with the formation of parties; along each of these lines of human interest, parties arise which the particular science in each case discusses. Yet we have no science which discusses the formation, rules and development of parties in general. The historical sciences investigate the most diverse cases of competition, but that which under the utmost diversity of material aim is common to all these cases, - the formation and importance of competition, treated purely as a reciprocal action among men-that has not yet been made a subject of investigation. And so it is with all those inter-subjective relations which bring it to pass that individuals become societies. The social forms in which men unite have not yet become an object of a special science, but are always treated in connection with the material subject-matter in which they are found and by the sciences covering this subjectmatter. On this account it seemed to me that the name Sociology was suited to that science which should treat these [42I] 
forms by means of inductive abstraction from the collective phenomena,-which always consist of a single content in a given form. It is the only science which really seeks to know only society, sensu strictissimo.

The scope of this science is moreover in no sense so narrow, as it appeared to a number of my critics. For not only does it embrace the most general forms of socialization, but also those which take place only in a limited number of combinations or determine only special phases of such. The importance, for example, of a common meal-time for the cohesion of individuals is a real sociological theme, likewise the differences in socializations which are connected with variations in the number of associates; the importance of the "non-partisan" in the conflict of members (Genossen); the "poor" as organic members of societies; the representation of bodies through individuals; the primus inter pares and the tertius gaudens. The different aspects of associations are to be determined according as they consist of locally connected or disconnected elements; and according as they are kept together through positive or merely defensive aims; according as they consist of the sum of all partakers or of some objective unity, above their single elements as such, formed by them; according as they are secret or public; and innumerable other problems of social formation can be solved only through inductive abstraction of forms from real cases in which they appear in a definite, historical subject-matter. Only after these particular formations are investigated in all their manifoldness from their primitive shape up to their most complicated development can we gradually solve the riddle, "What is Society?" For certainly it is not a unified being which lends itself readily to apt definition, but rather consists of the sum of all those modes and forces of association which unite its elements. Society is on the one side an entirely abstract general concept which has as little reality as general concepts usually have, the reality from which it is abstracted being 
the particular socializations; on the other hand it is a summing-up concept (Summirungsbegriff) made up of these single threads of association between individuals. I admit without hesitation that a great number of other groups of problems must be designated as social sciences, because the subject-matter which they treat appears only within society and can be understood only as social. But I can recognize as Sociology in the more exact sense, only that science which investigates the different kinds of combination of men as such.

\footnotetext{
University of Berlin.
}

GEORG SIMMEL. 